\section{Renal cell carcinoma with ipsilateral duplex system: Case report and review of literature}

Jideofor Okechukwu Ugwu, Okechukwu Hyginus Ekwunife, Chuka Abunike Ugwunne, Felix I. Menkiti, Andy Nwankwo Osuigwe

Department of Surgery, Nnamdi Azikiwe University Teaching Hospital, Nnewi, Nigeria

\begin{abstract}
Renal cell carcinoma is the most common malignant renal tumour in adults but quite rare in children. Duplex renal collecting systems are relatively common congenital renal abnormalities. However, its coexistence with renal cell carcinoma is yet to be established beyond a mere coincidence. So far, there are only 2 cases of such coexistence in literature till date. We therefore report a case of a 13-year-old girl who was referred to us with a right flank mass. Abdominal computerized tomographic scan revealed a right renal tumour necessitating a laparotomy at which a duplex collecting system was discovered in the ipsilateral kidney and a nephrouterectomy was done with a histologic finding of renal cell carcinoma. We report this rare relationship and review of literature to stimulate further study into this rare association.
\end{abstract}

\section{Introduction}

Ureteric duplication is a common congenital renal anomaly. ${ }^{1-3}$ The duplication may be complete or incomplete and are more common in females- $65 \%$ of the cases. ${ }^{1,3,4}$ Duplex systems are often associated with vesicoureteric reflux, urinary tract infections, ureteroceles and renal dysplasias. ${ }^{1}$ Its association with renal tumours are rather uncommon. Very few cases of duplex renal system associated with ipsilateral renal tumours have been reported in English literature and of these, there are only 2 cases of renal cell carcinoma and none in the paediatric population..$^{2,5}$

We therefore report a case of renal cell carcinoma (RCC) in a duplex renal system in a thirteen -year old Nigerian girl. The aim of this report is to heighten suspicion of this association and to stimulate further study in this domain.

\section{Case Report}

O.A., a 13- year old girl referred to Nnamdi Azikiwe University Teaching Hospital, Nnewi, Nigeria with a right flank swelling noticed a week prior to presentation. The swelling was painless, no haematuria, cough or yellowness of the eyes but there was associated weight loss. Examination findings revealed a ballotable firm right flank mass.

Abdominopelvic ultrasound scan showed moderately enlarged right kidney which harboured huge heterogenous echo mass in the lower and mid zones with multiple interspersed cystic centres. A computerized tomographic scan showed a right renal heterogenous mass lesion and suggested possibility of nephroblastoma, lymphoma, renal cell carcinoma or oncocytoma (Figure 1) but the duplex ureters were not highlighted. The blood count and serum electrolytes, creatinine and blood urea were all within normal limits.

She had exploratory laparotomy and the intraoperative findings were that of a haemorrhagic tumour involving largely the mid

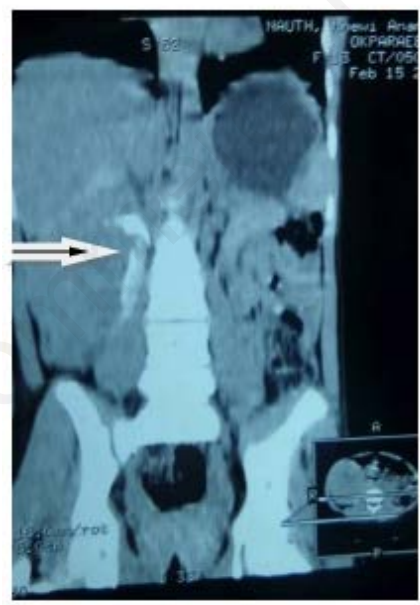

A

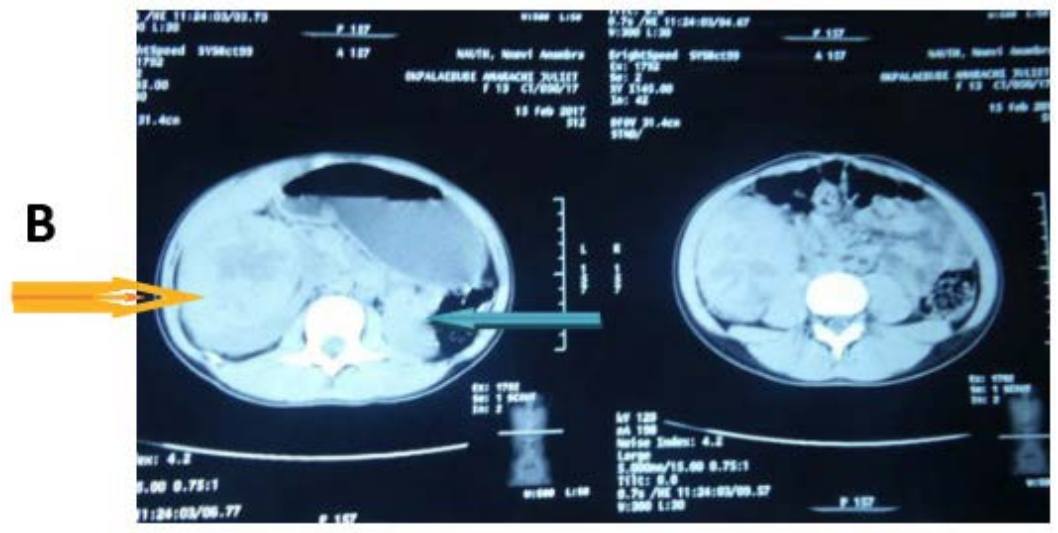

Figure 1. Coronal and axial computerized tomographic scan showing a huge right renal mass. The black arrow demonstrates the right duplex ureters, the orange arrow showing the right renal cell carcinoma and the blue arrow showing the contralateral functional normal kidney.
Correspondence: Jideofor Okechukwu Ugwu, Department of Surgery, Nnamdi Azikiwe University Teaching Hospital, Nnewi, Nigeria.

Email: ugwujideofor@yahoo.com

Key words: Childhood tumours, Congenital abnormalities, renal tumours, risk factors.

Contributions: The authors contributed equally.

Conflict of interest: The authors declare no potential conflict of interest.

Received for publication: 14 June 2019

Revision received: 10 October 2019

Accepted for publication: 10 October 2019.

This work is licensed under a Creative Commons Attribution NonCommercial 4.0 License (CC BY-NC 4.0).

${ }^{\circ}$ Copyright: the Author(s), 2019

Licensee PAGEPress, Italy

Pyramid Journal of Medicine 2019; 2:54 doi:10.4081/pjm.2019.54
Funding: None. 
and lower poles of the right kidney with normal appearing upper pole. There was a duplex ureter draining both $\mathrm{mid} /$ lower and upper poles respectively (Figure 2). There was no invasion of the capsule but there were enlarged lymph nodes. She had a right nephroureterectomy and lymphadenectomy and the histology report were that of renal cell carcinoma (clear cell variant) (Figure 3 ). She had 3 courses of chemotherapy with Vincristine and Actinomycin- D and then defaulted to re- present a 16 months later with recurrent right flank pain and swelling. She was subsequently evaluated for a recurrent right renal cell carcinoma. Re-exploration with tumour excision was done again. An intra-operative finding of a right lumbar tumour extending beneath the inferior vena cava. Histology finding was similar to the primary tumour A gross complete excision of the tumour was carried out. She was then placed on oral Sorafenib 200mg twice daily and has been followed up for a year now without recurrence.

\section{Discussion}

Renal cell carcinoma, though the most common malignant renal neoplasm in adults is extremely rare in children constituting about $3 \%$ of all malignant renal tumours in children. 6,7 It usually occurs between 2-17 years in children with a mean age of 8.5 years. ${ }^{6-8}$ There have been scanty reports of renal cell carcinoma occurring in

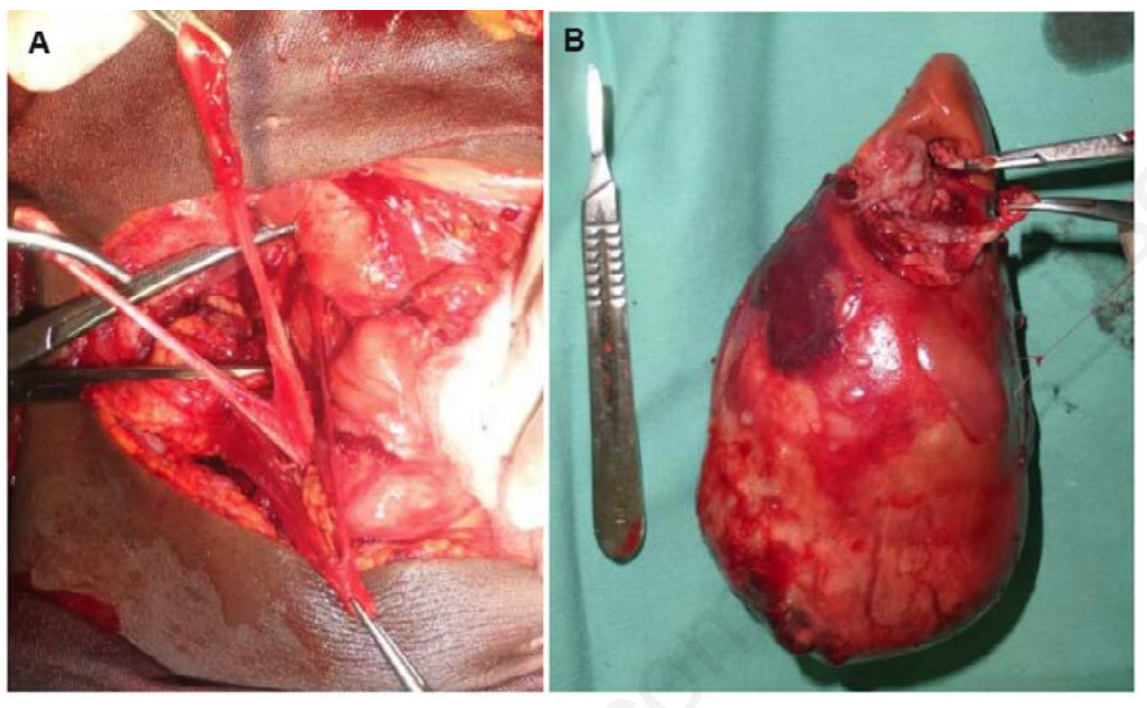

Figure 2. A) Intraoperative demonstration of the duplex ureters down to their confluence; B) Right Renal tumour with the duplex ureters at the hilum.

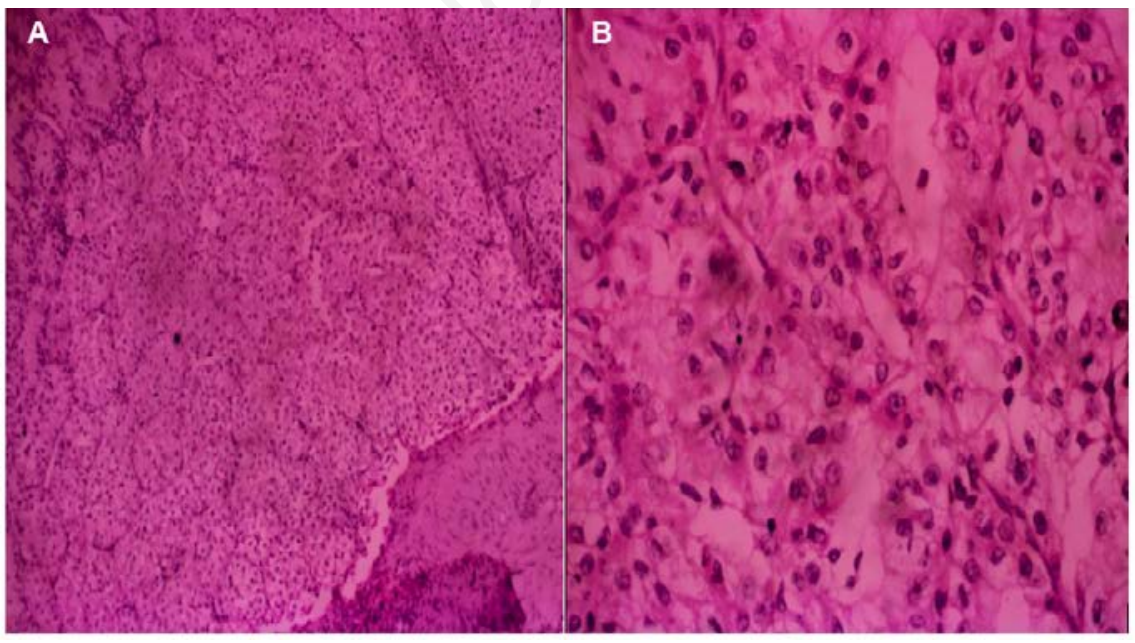

Figure 3. Photomicrographs showing alveolar nests of polygonal clear cells with intervening delicate branching vasculatures (A 50x; B 400x). These cells have clear cytoplasm and round central nuclei with prominent nucleoli. a duplex renal system. ${ }^{2,4}$ Mohan $^{2}$ and Khan et al. ${ }^{4}$ reported a case each of renal cell carcinoma occurring in a duplex renal system however both cases were in adult male patients. The index case is perhaps the first case of renal cell carcinoma in a duplex system in a child.

The exact pathogenesis of renal cell tumours in a duplex system is unknown, but it is thought to be as a result of continuous injury from infection, trauma, inflammation and calculi. ${ }^{9}$ In this case, the irritation might have been as a result of back pressure effect and turbulence at the junction since the duplication was not complete. The presentation of RCC in children is different from that of adults. The index case was a 13-yearold girl which is in keeping with the age range for RCC in children. ${ }^{6-8}$ The most common complaint is that of haematuria as

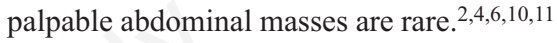
she did not present with haematuria rather with palpable right flank mass and weight loss. Further evaluations are usually carried out with imaging modalities such as abdominopelvic ultrasound scan, computerized tomographic scan and intravenous urography. ${ }^{2,4}$ Despite these, it is difficult to differentiate RCC in children from Wilm's tumour before surgery and histology and this was the case with our patient whose diagnosis was only made after histopathology. There is no standard treatment protocol for the treatment of RCC s in children, so far surgical extirpation has been the main stay of treatment. ${ }^{2,4}$ Renal conserving surgeries are feasible in some select cases in duplex system as it largely affects the lower poles more. ${ }^{2,4}$ Khan et al. ${ }^{4}$ performed renal conserving surgery on a patient but this was not carried out the index case $t$ as the available normal upper pole was quite small. RCC $s$ are neither chemosensitive or radiosensitive. The usefulness of these modalities as adjuvants in children are yet to be determined with scanty individual variable protocols. ${ }^{11,12}$ We had commenced the patient on adjuvant chemotherapy with Vincristine and Actinomycin D but patient defaulted after 3 courses and returned after a period of 16 months with recurrence. There is no established adjuvant chemotherapy against renal cell carcinoma. Abdellah et al. ${ }^{11}$ did not give adjuvant chemotherapy to their patient and there was no recurrence. The index patient was commenced on oral Sorafenib. Sorafenib is a targeted therapy which has been found to be effective in managing advanced renal cell carcinomas and hepatocellular carcinomas. ${ }^{13}$ The nondevelopment of standard treatment protocol may not be unconnected to rarity of this tumour in children. 


\section{Conclusions}

RCC in paediatric age group is quite rare and reports are emerging of its occurrence in patients with ipsilateral duplex renal system. It remains to be determined whether there is a causal relationship between the two or a mere chance event. Further surveillance on this association and standardized treatment protocol is hereby recommended.

\section{References}

1. Clark JD. Ureteral duplications and ureteroceles. In: O'Neil JA Jr. Paediatric Surgery. 5th Ed. Mosby Year Book Inc. 1998. pp 1623-1629.

2. Mohan H, Kundu R, Dalal U. Renal cell carcinoma arising in ipsilateral duplex system. Turk J Urol 2014;40:185-8.

3. Whitten SM, Wilcox DT. Duplex systems. Prenat Diagn 2001;21:952-7.

4. Khan AA. Renal Cell Carcinoma at lower pole moiety of adult left duplex kidney. J Postgraduate Med Inst 2015;29:313-6.

5. Chen KS, Chuang CK, Wu CH, et al. Upper urinary tract tumor in a duplicated collecting system. Report of 3 cases and review of literature. Chang Gung Med J 2003;26:377-82.

6. Estrada CR, Suthar AM, Eaton SH, Cilento BG Jr. Renal Cell Carcinoma: Children's Hospital Boston Experience. Urology 2005;66:1296-300.

7. Bosquet M, Dominguez C, Balagner J, et al. Paediatric renal adenocarcinoma: A review of our series. Urology 2008;72:790-3.

8. Asanuma H, Nakai H, Takeda M, et al. Renal cell carcinoma in children.
Experience at a single institution in Japan. J Urol 1999;16:1402-5.

9. Ujike T, Noda Y, Oka D, et al. Squamous cell carcinoma of the renal pelvis with giant hydronephrosis. Hinyokikakiyo 2003;49:757-9.

10. Indolfi P, Terenziani M, Casale M, et al. Renal cell carcinoma in children: A clinicopathologic study. J Clin Oncol 2003;121:530-5.

11. Abdellah A, Selma K, Elamin M, et al. Renal cell carcinoma in children: case report and literature review. Pan Afr Med J 2015;20:84.

12. Geller JI, Argani P, Adeniran A, et al. Translocation renal carcinoma; lack of negative impact due to lymph node spread. Cancer 2008;112:1607-16.

13. Guevremont C, Jeldres C, Perrotte P, Karakiewicz PI. Sorafenib in the management of metastatic renal cell carcinoma. Curr Oncol 2009;16:S27. 